\title{
Diversity, Composition and Functional Inference of Gut Microbiota in Indian Cabbage white Pieris canidia (Lepidoptera: Pieridae)
}

\author{
Ying Wang ${ }^{1,{ }^{\dagger}}$, Jianqing Zhu ${ }^{2,+}{ }^{\dagger}$, Jie Fang ${ }^{1}$, Li Shen ${ }^{1}$, Shuojia Ma ${ }^{1}$, Zimiao Zhao ${ }^{1}$, Weidong Yu ${ }^{1}$ \\ and Weibin Jiang $1, *$ (1) \\ 1 Laboratory of Environmental Entomology, College of Life Sciences, Shanghai Normal University, \\ 100 Guilin Rd., Shanghai 200234, China; 1000460649@smail.shnu.edu.cn (Y.W.); \\ 1000479678@smail.shnu.edu.cn (J.F.); 1000479682@smail.shnu.edu.cn (L.S.); \\ 1000459151@smail.shnu.edu.cn (S.M.); 1000459159@smail.shnu.edu.cn (Z.Z.); ywd@shnu.edu.cn (W.Y.) \\ 2 Shanghai Zoological Park, 2381 Hongqiao Rd., Shanghai 200335, China; zzzjjq@gmail.com \\ * Correspondence: jiangwb@shnu.edu.cn \\ + These authors contributed equally to this work.
}

Received: 12 October 2020; Accepted: 23 October 2020; Published: 25 October 2020

\begin{abstract}
We characterized the gut microbial composition and relative abundance of gut bacteria in the larvae and adults of Pieris canidia by $16 \mathrm{~S}$ rRNA gene sequencing. The gut microbiota structure was similar across the life stages and sexes. The comparative functional analysis on $P$. canidia bacterial communities with PICRUSt showed the enrichment of several pathways including those for energy metabolism, immune system, digestive system, xenobiotics biodegradation, transport, cell growth and death. The parameters often used as a proxy of insect fitness (development time, pupation rate, emergence rate, adult survival rate and weight of 5 th instars larvae) showed a significant difference between treatment group and untreated group and point to potential fitness advantages with the gut microbiomes in P. canidia. These data provide an overall view of the bacterial community across the life stages and sexes in P. canidia.
\end{abstract}

Keywords: Indian cabbage white; gut microbiome; $16 \mathrm{~S}$ rDNA sequencing; developmental stage

\section{Introduction}

Pieris canidia (Sparrman, 1768), the Indian cabbage white, is a major pest of crucifer plants in several countries of Asia [1]. It consumes leaf tissue, causes deficit disease and reduces production of crops. The chemical insecticide is the main control method at present, but it results in the increase of resistance to the pesticide, ecological environment deterioration and human health impaired with pesticide residues [2]. Thus, the development of bio-control techniques for agricultural pests is a research prospect for pollution-free vegetable production [3].

In the process of evolution, the gut microbiomes of insects interact and co-evolve with their hosts [4]. The gut microbiota plays crucial roles in the growth, development and immunity of the host insects [5]. The correlation between gut microbiota of the insect and the resistance of chemical insecticide provides a new perspective for comprehensive control of agricultural pests. The relationship between gut microbiomes and feeding behavior of their hosts also provides a theoretical model for insect evolution studies. Furthermore, the interaction between gut microbiomes and host immune systems is an ideal model for the study of insect immune mechanisms, which contributes to the biological control of pests and development of pesticide targets [6].

Hammer et al. [7] characterized the gut microbiomes of 185 wild lepidopteran caterpillars from 124 species of 15 families with $16 \mathrm{~S}$ rRNA gene sequencing and quantitative PCR. The microbes 
detected in caterpillar guts were low-density and variable among individuals compared with other insects and vertebrates. In nearly 300 adult butterflies representing over 50 species from six families, Ravenscraft et al. [8] did not find a lot of bacteria load of gut microbiomes but indicated that the majority of variation in the butterfly gut flora is expressed at the level of the individual host, followed by host species. Their results show that caterpillars lack a resident gut microbiome, and the gut microbial community composition varies across host individuals.

In this study, we characterized gut microbial abundance and composition of the larvae and adults via $16 \mathrm{~S}$ rRNA gene sequencing and observed the development and fitness of butterflies treated with antibiotics. We laid the foundation for a mechanistic understanding of how this hidden symbiosis affects and is affected by its host.

\section{Materials and Methods}

\subsection{Sampling, Sequencing and Bioinformatics Analyses}

The $P$. canidia butterflies used in this study were collected from three wild populations (Xuhui $\mathrm{N} 31.22^{\circ} \mathrm{E} 121.48^{\circ}$, Songjiang N 31.00 $\mathrm{E} 121.24^{\circ}$ and Chongming N $31.73^{\circ} \mathrm{E} 121.40^{\circ}$ ) in Shanghai, China in June 2019. The adults were caught with a sweep net in the field, and the larvae were found on their host plants Brassica campestris L. We collected twenty adults (10 females and 10 males) and twenty of the last instar larvae (10 females and 10 males) in each local population. These insects were dissected and the gut samples preserved with dry storage at $-20{ }^{\circ} \mathrm{C}$. The storing method for insect microbiome samples does not substantially alter community composition [9]. Each ten dissected tissues of a same group within each population were pooled as a sample to extract DNA. We extracted DNA with a Powersoil DNA isolation kit and protocol (MoBio, CA, USA). The 16S rRNA V3-V4 gene section was conducted with PCR amplification with barcoded primers 357F (5'-ACTCCTACGGRAGGCAGCAG-3') and 806R (5'-GGACTACNVGGGTWTCTAAT-3') and the methods from Liu et al. [10]. Libraries were pooled, and 450-bp paired end reads were sequenced on an Illumina MiSeq sequencer.

The paired-end fastq files of $16 \mathrm{~S}$ rRNA amplicons generated by Illumina were used as input files. Sequences were pre-processed, quality filtered and clustered into operational taxonomic units (OTU) at the 97\% sequence similarity level using UPARSE [11]. They were annotated and classified using the Ribosomal Database Project (RDP) classifier and Greengenes $[12,13]$. We used one-way ANOVA to determine whether there were significant differences in community richness or the relative abundances of individual bacterial taxa.

Predicted functions of P. canidia bacterial communities were inferred using PICRUSt [14]. The analysis was performed by the predict_metagenomes.py script run against the functional database of KEGG Orthology. Functional contributions of various taxa to different KOs were computed with the script metagenome_contributions.py $[15,16]$.

\subsection{Antibiotic Experiment}

We collected P. canidia eggs of a Xuhui population ( $\mathrm{N} 31.22^{\circ}$ E $\left.121.48^{\circ}\right)$ from B. campestris plants. Two hundred and forty newly hatched larvae were randomly and evenly divided into three tetracycline treatment groups $(0.56 \mathrm{mg} / \mathrm{mL}, 1.12 \mathrm{mg} / \mathrm{mL}$ and $1.68 \mathrm{mg} / \mathrm{mL})$ and a control group. The antibiotics used here have been shown to suppress bacterial symbionts in other insect [17]. Water with or without antibiotics was sprayed onto leaves, which were then briefly dried before feeding according to Hammer et al. [7]. Each group had six biological replicates and each replicate included 10 larvae. Each replicate was reared in a separate plastic case (dimensions of $15 \mathrm{~cm} \times 15 \mathrm{~cm} \times 10 \mathrm{~cm}$ ) on B. oleracea foliage and transferred to a butterfly cage (dimensions of $28 \mathrm{~cm} \times 28 \mathrm{~cm} \times 30 \mathrm{~cm}$ ) when they were 5 th instars.

We compared development time, pupation rate, emergence rate, adult survival rate and weight of 5 th instars larvae between tetracycline treated $(0.56 \mathrm{mg} / \mathrm{mL}, 1.12 \mathrm{mg} / \mathrm{mL}$ and $1.68 \mathrm{mg} / \mathrm{mL})$ and untreated groups by one-way ANOVA. These parameters are often used as a proxy of insect fitness $[18,19]$. All analyses were conducted using SPSS statistics version 21.0 for Windows (SPSS Inc., Chicago, IL, USA). 


\section{Results}

\subsection{Bacterial Community Diversity and Predicted Functional Metagenomes in P. canidia}

The raw sequence data obtained in this study were deposited in The National Center for Biotechnology Information (NCBI) under accession number SRS5823888-SRS5823899. Raw sequences clustered into 509 operational taxonomic units (OTUs) across the 12 samples (Table 1). These OTUs were annotated into 12 phyla, 24 classes, 45 orders, 78 families and 120 genera (Table 2), of which 39 OTUs were shared across all groups (Supplementary Materials Figure S1) and 4 OTUs were shared across all samples (Figure S2). Sufficient sequencing data were obtained based on the plateaued rarefaction curves of obvious species (Figure S3). Based on the OTU abundance information (97\% similarity), the relative abundance of each OTU in each sample was calculated, and the PCA (principal component analysis) of OTU was done with the relative abundance value (Figure 1). Coordinate dots of female larvae and male larvae samples were closely located.

Table 1. Dominant bacterial phylotypes in P. canidia.

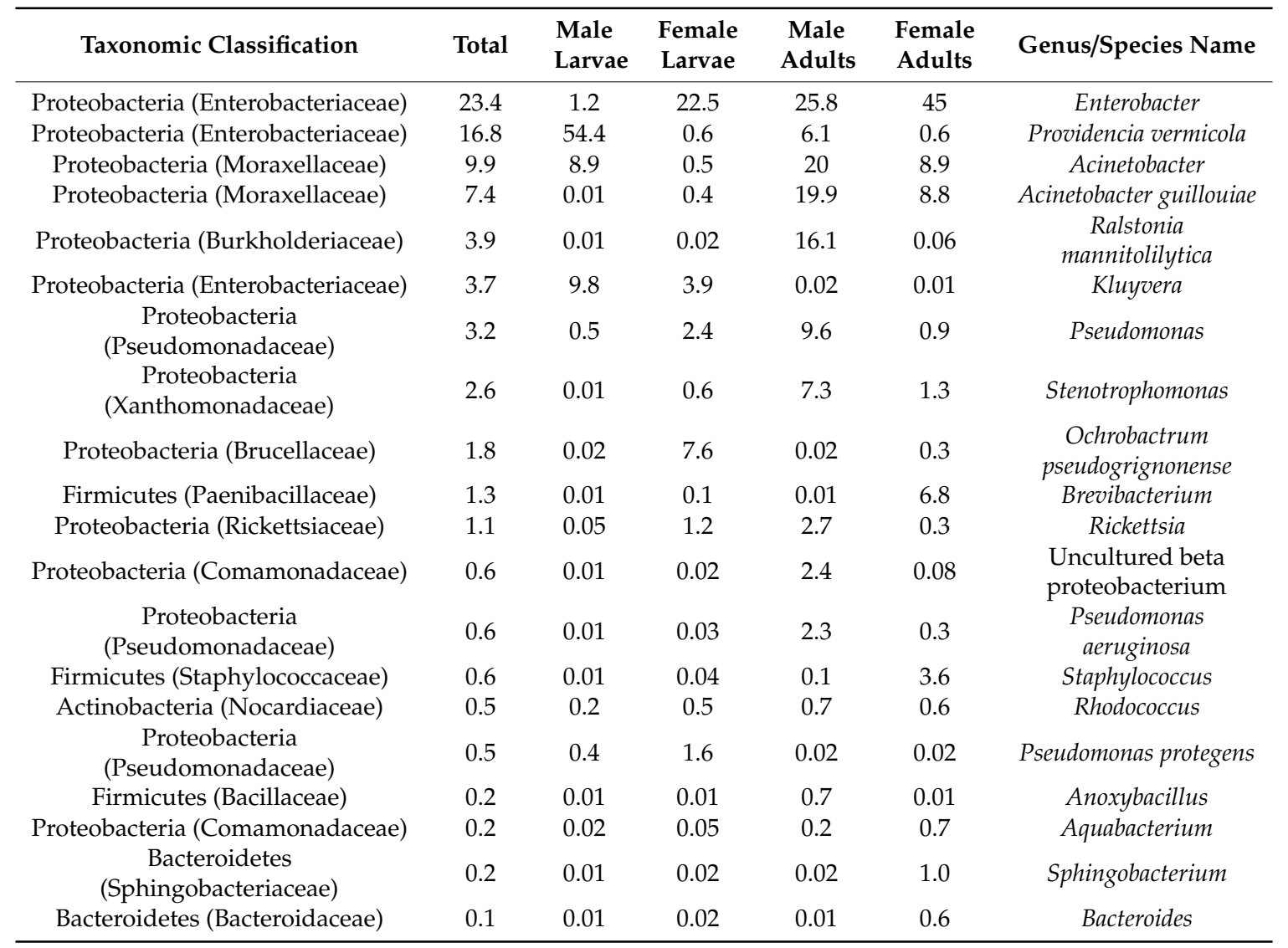

Bacterial phylotype richness did not show a significant difference among life stages and sexes $\left(F_{(3,8)}=0.013, p=0.998\right)$. Nearly identical patterns were observed when diversity was measured using the Simpson index (Figure 2), which takes relative abundances into account $\left(\mathrm{F}_{(3,8)}=1.196, p=0.371\right)$. A comparison restricted to only the numerically dominant phylotypes (at least $1 \%$ ) produced a similar pattern $\left(F_{(3,8)}=2.628, p=0.122\right)$. Gut bacteria of larval samples were more diversified than those of adult samples, which were derived from five diversity estimators in Table 3. Higher value of observed species (sobs), Chao, Ace, Simpson's index and lower Shannon's index in male larvae and female larvae groups suggested that gut bacteria from larval guts were more diverse than those from the adult stage. 
Table 2. Samples and their sequencing data processing.

\begin{tabular}{cccc}
\hline Sample Name & Clean Reads & Tags & OTUs \\
\hline Male larva 1 & 30,832 & 28,467 & 78 \\
Male larva 2 & 31,836 & 29,642 & 89 \\
Male larva 3 & 35,873 & 33,895 & 40 \\
Female larva 1 & 30,150 & 24,244 & 128 \\
Female larva 2 & 25,145 & 23,521 & 45 \\
Female larva 3 & 25,612 & 23,003 & 48 \\
Male adult 1 & 38,990 & 36,377 & 86 \\
Male adult 2 & 26,316 & 24,431 & 44 \\
Male adult 3 & 27,648 & 24,893 & 82 \\
Female adult 1 & 47,496 & 20,165 & 69 \\
Female adult 2 & 46,537 & 15,318 & 62 \\
Female adult 3 & 26,431 & 24,109 & 80
\end{tabular}

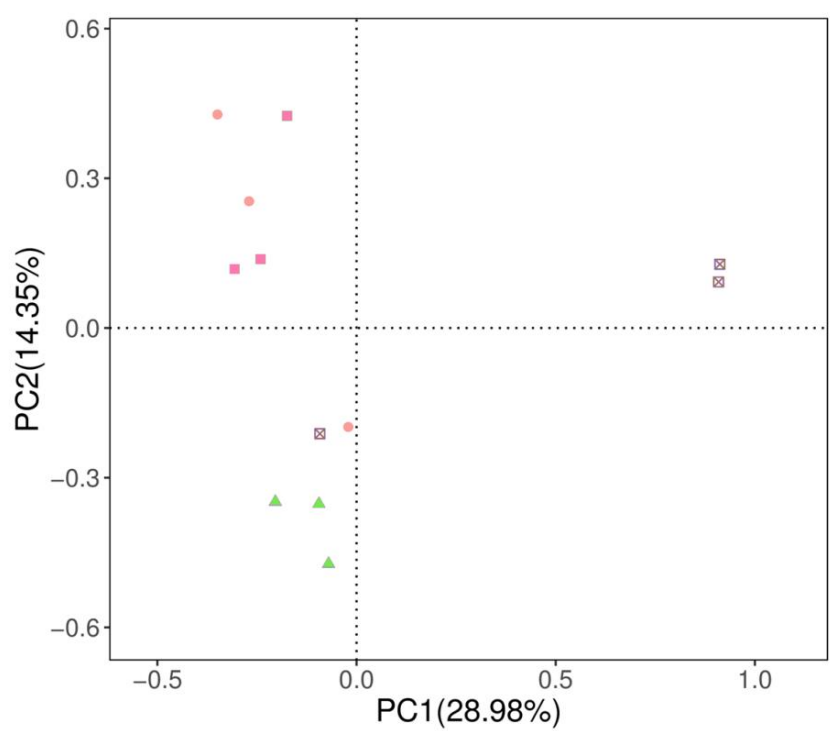

male larvae

- female larvae

$\triangle$ male adults

female adults

Figure 1. Principal component analysis based on operational taxonomic units (OTUs). X-axis, 1st principal component; Y-axis, 2nd principal component. Numbers in parentheses represent the contributions of the principal components to differences among samples. Dots represents individual samples, and different colors represent different groups.

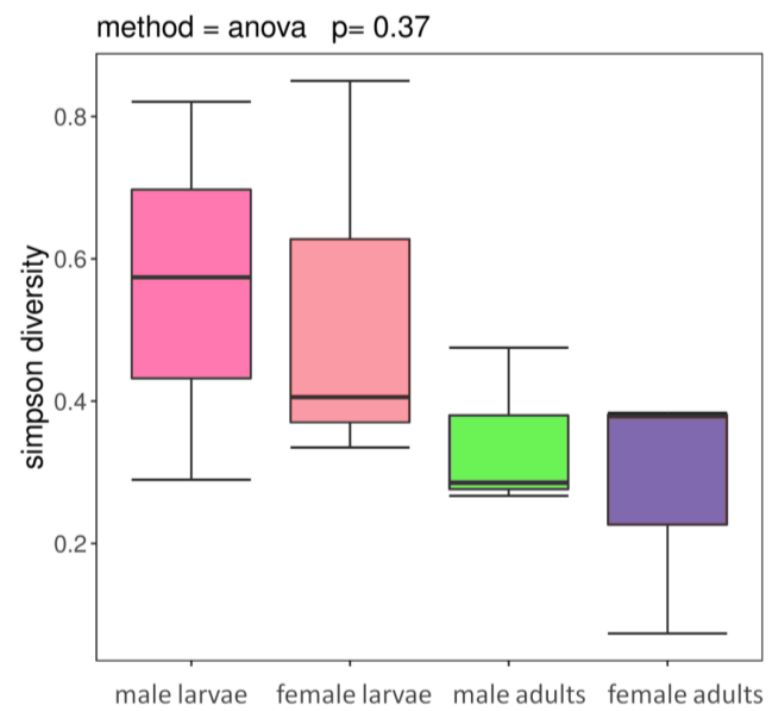

Figure 2. Changes in bacterial community diversity across life stages and sexes. Boxplot of Simpson Diversity Index values from $P$. canidia male larvae, female larvae, male adults and female adults. 
Table 3. Bacterial alpha diversity of $P$. canidia in different groups based on the $16 \mathrm{~S}$ rDNA amplicon.

\begin{tabular}{cccccc}
\hline & Sobs (Observed Species) & Chao & Ace & Shannon & Simpson \\
\hline Male larvae & $69 \pm 5.71$ & $84.85 \pm 17.65$ & $103.53 \pm 15.19$ & $0.93 \pm 0.51$ & $0.56 \pm 0.27$ \\
Female larvae & $73.67 \pm 7.08$ & $97.5 \pm 7.08$ & $103.94 \pm 6.53$ & $1.10 \pm 0.55$ & $0.53 \pm 0.08$ \\
Male adults & $70.67 \pm 23.18$ & $88.73 \pm 30.36$ & $95.71 \pm 9.06$ & $1.53 \pm 0.35$ & $0.34 \pm 0.12$ \\
Female adults & $70.33 \pm 9.07$ & $74.22 \pm 11.19$ & $77.21 \pm 12.68$ & $2.16 \pm 0.94$ & $0.28 \pm 0.08$ \\
\hline
\end{tabular}

The four groups of P. canidia (male larvae, female larvae, male adults and female adults) were dominated by six bacterial families: the Enterobacteriaceae and Moraxellaceae (Gammaproteobacteria), Burkholderiaceae (Betaproteobacteria), Pseudomonadaceae and Xanthomonadaceae (Gammaproteobacteria), and Brucellaceae (Alphaproteobacteria). Although family-level bacterial community composition varied substantially between individuals of the same life stage in some cases, three families including Moraxellaceae, Pseudomonadaceae and Xanthomonadaceae shifted significantly in relative abundance across the life stages and sexes (Figure 3, Bonferroni-corrected, $p<0.05$ ). The 20 most abundant phylotypes present across all four groups of $P$. canidia samples are listed in Table 1 . The split between larval and adult communities appears to be driven by the higher relative abundance of Kluyvera in the larvae and of Acinetobacter guillouiae and Stenotrophomonas in the mature adults.
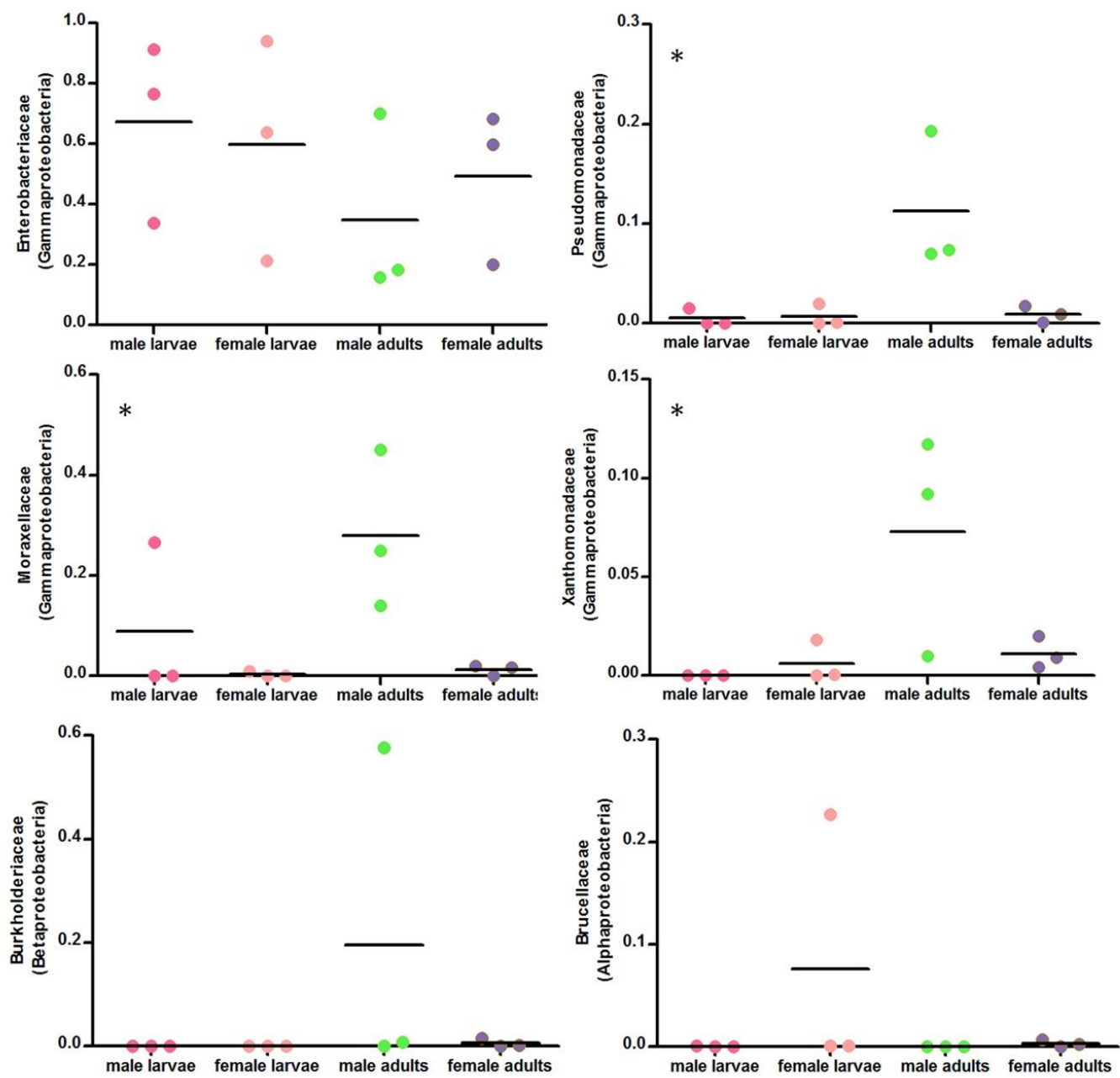

Figure 3. Dynamics of bacterial families across life stages and sexes. Relative abundances of the six dominant bacterial families in P. canidia were displayed. Points show three individual values. Bars show average relative abundances. Asterisks indicate bacterial families whose relative abundances differed significantly across life stages $\left({ }^{*} p<0.05,{ }^{* *} p<0.01\right)$. 
We predicted functional potentials of the microbial community associated with the four groups of P. canidia (male larvae, female larvae, male adults and female adults) using the PICRUSt (Figure 4), which is a computational approach to predict the functional composition of a metagenome using marker gene data and a database of reference genomes [14]. It is a conventional and effective method to infer the microbiota functional potential across the stages using PICRUSt. These functional categories, including nervous systems and translation, were enriched in the larvae, whereas in the adults, cell motility, circulatory system, transcription, metabolism and associated relative gene copy numbers were increased by approximately $50 \%$. The enrichment of several other pathways, including those for energy metabolism, immune system, digestive system, xenobiotics biodegradation, transport, cell growth and death, were observed in microbiome of all four groups.

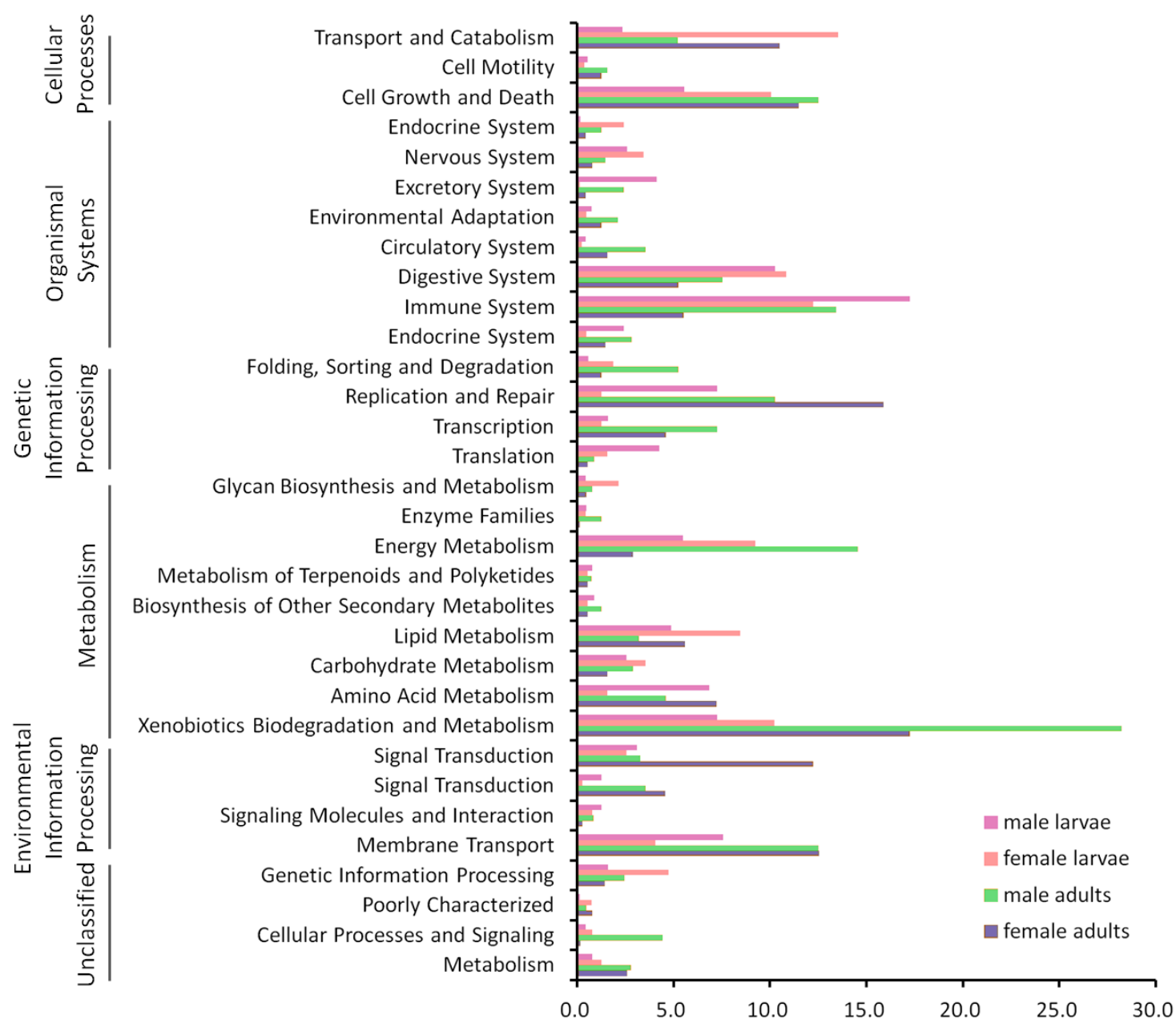

Figure 4. Inferred functions of bacterial communities associated with P. canidia. All of the predicted KEGG metabolic pathways are shown at the second hierarchical level and grouped by major functional categories.

\subsection{Fitness of P. canidia Treated with Antibiotics}

The data of insect fitness parameters (development time, pupation rate, emergence rate, adult survival rate and weight of 5 th instars larvae) are showed in Table 4 . For development time, the ANOVA showed a significant difference among three tetracycline treatment groups $(0.56 \mathrm{mg} / \mathrm{mL}, 1.12 \mathrm{mg} / \mathrm{mL}$ and $1.68 \mathrm{mg} / \mathrm{mL}$ ) and the untreated group (Figure $5 \mathrm{~A}$ ). The larvae and pupae with tetracycline treatment had a longer development time than those untreated $\left(\mathrm{F}_{(3131)}=92.92, p<0.01\right.$ and $\mathrm{F}_{(3138)}=18.09$, $p<0.01)$. The adults had a shorter life span when they were treated with antibiotics $\left(\mathrm{F}_{(3137)}=55.28\right.$, $p<0.01)$. 
Table 4. The data of insect fitness parameters.

\begin{tabular}{ccccccccc}
\hline $\begin{array}{c}\text { Tetracycline } \\
\text { Treatment }\end{array}$ & Group & \multicolumn{2}{c}{ Development Time (Days) } & $\begin{array}{c}\text { Weight of 5th } \\
\text { Instars Larvae (g) }\end{array}$ & $\begin{array}{c}\text { Pupation } \\
\text { Rate }\end{array}$ & $\begin{array}{c}\text { Emergence } \\
\text { Rate }\end{array}$ & $\begin{array}{c}\text { Adult } \\
\text { Survival Rate }\end{array}$ \\
\cline { 3 - 8 } $1.68 \mathrm{mg} / \mathrm{mL}$ & 1 & 16 & 7 & 6 & 0.0401 & 0.50 & 1.00 & 0.50 \\
& & 13 & 7 & 5 & 0.0241 & & & \\
& & 15 & 5 & 6 & 0.0234 & & & \\
& & 14 & 7 & 5 & 0.0331 & & & \\
& 13 & 7 & 6 & 0.0215 & & & \\
\end{tabular}
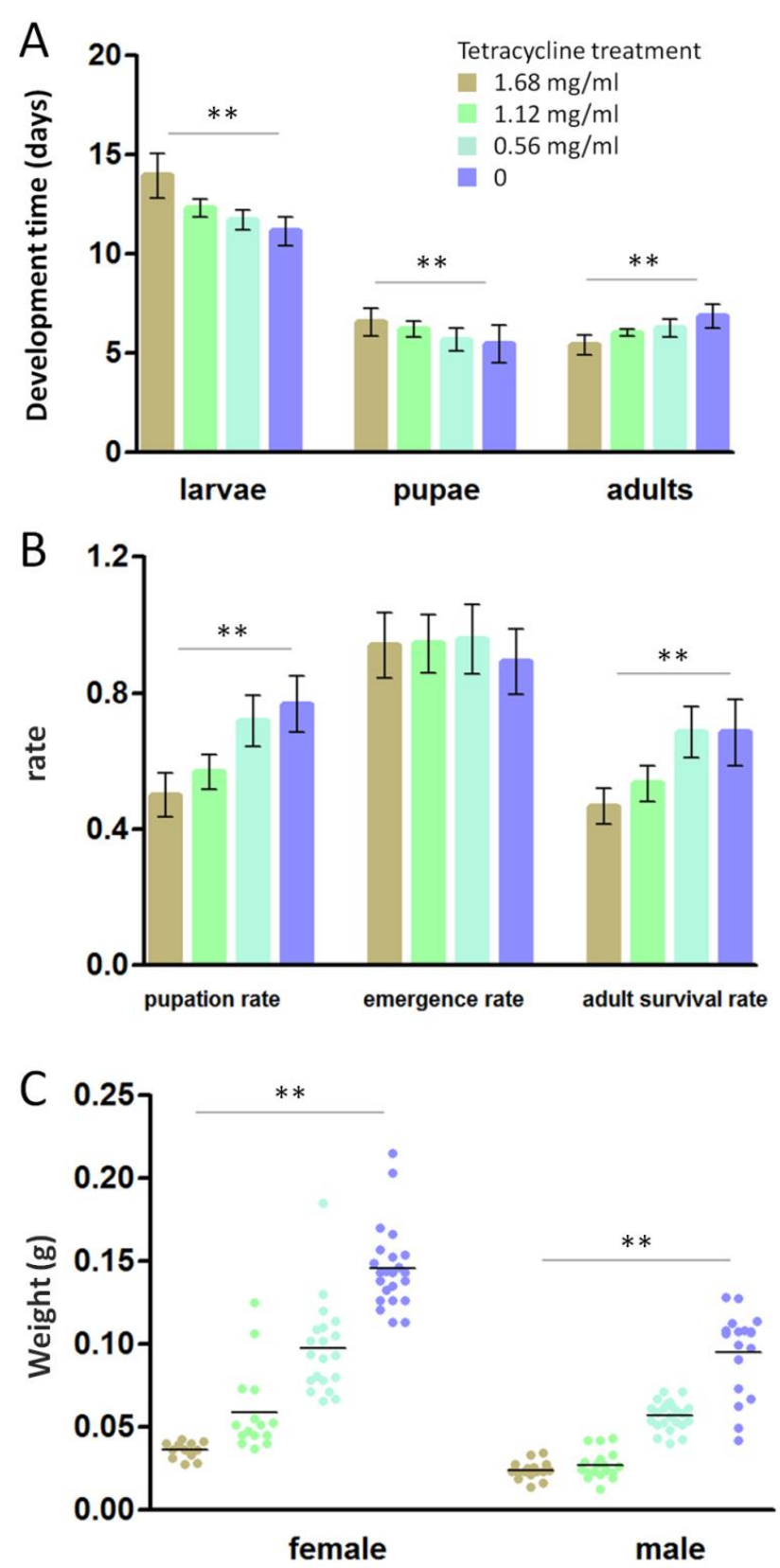

Figure 5. The histograms are for (A) development time and (B) pupation rate, adult survival rate and emergence rate. The scatter diagram is for $(\mathbf{C})$ weight of female and male 5 th instars. The bars represent mean \pm standard deviation $(\mathrm{n}=3)$, and $\mathrm{F}$ tests were used to determine the difference across different concentration of tetracycline treatment $\left(* p<0.05,{ }^{* *} p<0.01\right)$. 
The pupation rate was lower when the antibiotics were present and decreased with concentration (Figure 5B), resulting in a significant effect of the antibiotic condition on this variable $\left(\mathrm{F}_{(3,20)}=19.74\right.$, $p<0.01)$. A similar significant effect was observed on the adult survival rate $\left(\mathrm{F}_{(3,30)}=13.87, p<0.01\right)$. The emergence rate was higher when treated with antibiotics but showed no significant difference from those untreated $\left(\mathrm{F}_{(3,20)}=0.55, p=0.66\right)$.

The weights of female and male adults were significantly higher than those treated with antibiotics $\left(\mathrm{F}_{(3,66)}=70.65, p<0.01\right.$ and $\left.\mathrm{F}_{(3,71)}=95.95, p<0.01\right)$. The weight was lower when the antibiotics were present and increased with concentration (Figure $5 \mathrm{C}$ ).

\section{Discussion}

The composition of gut microbiomes in lepidopterans is relatively simple [20-22]. In this study, the 10 most abundant phylotypes accounted for $74 \%$ of the sequences from all P. canidia samples, which showed an uneven structure of the bacterial communities. Hammer et al. [7] and Ravenscraft et al. [8] reported that caterpillars lack a resident gut microbiome, and the gut microbial community composition varies across adult butterflies. The high $\mathrm{pH}$ values $(>10)$ in gut [23], host-encoded digestive and detoxification peptides [24], simple gut structure of tube-like morphology [25] and fast food transit times may be unfavorable to microbial growth.

Despite the relatively simple composition and low densities of lepidopteran gut microbiomes $[7,20-$ 22], this study points to potential fitness advantages with the gut microbiomes in P. canidia. The fitness advantages relate to a faster development time, a longer life span of adults, higher pupation and adult survival rates and a heavier weight (Figure 5). After the butterflies were treated with difference concentration of tetracycline $(0.56 \mathrm{mg} / \mathrm{mL}, 1.12 \mathrm{mg} / \mathrm{mL}$ and $1.68 \mathrm{mg} / \mathrm{mL})$, these parameters, which are often used as a proxy of insect fitness, showed a significant difference among the treatment group and untreated group.

We characterized gut microbial abundance and composition of the larvae and adults via $16 \mathrm{~S}$ rRNA gene sequencing and found some abundant phylotypes present across all larvae and adult butterflies samples. The isolate in the genus Enterobacter is the phylotype with the highest abundance across all P. canidia samples. Enterobacter are found to have cellulolytic activity to degrade carbohydrates and may be useful for digestion by the host insect [26]. The cellulose degrading bacteria are suggested to have the ability to utilize xylan, which is a polymer made of $\beta-1,4$ xylosidic bonds [27]. Potrikus and Breznak [28] reported Enterobacter agglomerans, isolated from guts of wood-eating termites, has nitrogen-fixing activity and may be important for the nitrogen economy of the termites.

The other three genera of bacteria examined from all P. canidia samples were Acinetobacter, Aquabacterium and Rhodococcus. The denitrifying genus Acinetobacter and Aquabacterium are commonly present in other insects. They have been shown to confer nutritional benefits including nitrogen removal and intestinal nutrient substance metabolism [29-31]. The genus Rhodococcus plays an important role in the degradation of toxins, such as monoterpene and isoprene, which is harmful to insect fitness [32].

A phylotype matching a Stenotrophomonas clone was also abundant. The genus contains species ranging from common soil organisms (S. nitritireducens) to opportunistic human pathogens (S. maltophilia) [33]. Stenotrophomonas sequences have been reported from other lepidopteran species including Plodia interpunctella [34] and Antheraea assamensis [35], although their possible role in host herbivory is not well understood. Wang et al. [36], reported a strain of S. maltophilia from the mesophilic microbial community BYND-8 to be cellulolytic.

The genera Staphylococcus and Pseudomonas, which are a group of pathogenic bacteria, may cause host insect diseases. When silkworm larvae were fed on mulberry leaves smeared with a bacterial solution of Staphylococcus, the gene expression of gloverin and lysozyme was upregulated. When silkworm larvae were fed on mulberry leaves smeared with a bacterial solution of Pseudomonas, the gene expression of gloverin 2 and gloverin 3, as well as the genes of the immune related pathway 9 were upregulated. This indicates that both genera are closely related to the immune signaling pathway of the insect [37]. Rickettsia can affect the fitness of their hosts, especially under stress. Himler et al. [38] 
found that compared with uninfected whiteflies, Rickettsia-infected whiteflies produced more offspring, had higher survival to adulthood, developed faster and produced a higher proportion of daughters.

\section{Conclusions}

This study used $16 \mathrm{~S}$ rRNA gene sequencing to clarify the gut microbiome across the life stages and sexes of $P$. canidia and compared the fitness of butterflies treated and untreated with antibiotics. These results suggested that the gut microbiota of P. canidia was relatively simple but played a potential role in fitness advantage for its host. The gut bacteria are useful for digestion, nutrient substance metabolism, toxin degradation and immune signaling pathway activity.

Supplementary Materials: The following are available online at http:/www.mdpi.com/2075-1729/10/11/254/s1, Figure S1: Petal diagram of OTU distribution across P. canidia life stages and sexes. Numbers within compartments indicate OTU counts according to mathematical sets.; Figure S2: Petal diagram of OTU distribution across all samples. Numbers within compartments indicate OTU counts according to mathematical sets.; Figure S3: Rarefaction curve based on OTUs. Mothur (v1.31.2) was used to calculate indices for rarefaction curve based on observed species values.

Author Contributions: Conceptualization, W.J.; methodology, Y.W., J.F. and L.S.; analysis, S.M., Z.Z. and W.Y.; resources, W.Y. and J.Z.; writing—original draft preparation, W.J;; writing—review and editing, J.Z. and W.Y.; supervision, W.J. All authors have read and agreed to the published version of the manuscript.

Funding: This study was financially supported by grants from National Natural Science Foundation of China (No.31401997), Shanghai Natural Science Foundation (20ZR1440800) and Shanghai Municipal Human Resources and Social Security Bureau (No.2019112).

Acknowledgments: Authors are thankful to anonymous reviewers for their valuable feedback and suggestions on a previous draft of this manuscript.

Conflicts of Interest: The authors declare no conflict of interest.

Availability of Data and Material: The raw sequence data obtained in this study were deposited in the Bioproject of The National Center for Biotechnology Information (NCBI) under accession number PRJNA595480 (https://www.ncbi.nlm.nih.gov/bioproject/PRJNA595480). All authors approved the disclosure of data because this study did not involve human subjects.

\section{References}

1. Evans, W.H. The Identification of Indian Butterflies, 2nd ed.; Bombay Natural History Society: Mumbai, India, 1932; p. 152.

2. Hernández-Martínez, P.; Naseri, B.; Navarro-Cerrillo, G.; Escriche, B.; Ferré, J.; Herrero, S. Increase in midgut microbiota load induces an apparent immune priming and increases tolerance to Bacillus thuringiensis. Environ. Microbiol. 2010, 12, 2730-2737. [CrossRef] [PubMed]

3. Lamichhane, J.R.; Schaefer, M.B.; Bluemel, S.; Dachbrodt-Saaydeh, S.; Dreux, L.; Jansen, J.P.; Kiss, J.; Köhl, J.; Kudsk, P.; Malausa, T. Identifying obstacles and ranking common biological control research priorities for Europe to manage most economically important pests in arable, vegetable and perennial crops. Pest Manag. Sci. 2017, 73, 14-21. [CrossRef] [PubMed]

4. Provorov, N.A.; Onishchuk, O.P. Microbial symbionts of insects: Genetic organization, adaptive role, and evolution. Microbiology 2018, 87, 151-163. [CrossRef]

5. Krishnan, M.; Bharathiraja, C.; Pandiarajan, J.; Prasanna, V.A.; Rajendhran, J.; Gunasekaran, P. Insect gut microbiome -An unexploited reserve for biotechnological application. Asian Pac. J. Trop. Biomed. 2014, 4, S16-S21. [CrossRef]

6. Raymann, K.; Moran, N.A. The role of the gut microbiome in health and disease of adult honey bee workers. Curr. Opin. Insect Sci. 2018, 26, 97-104. [CrossRef]

7. Hammer, T.J.; Janzen, D.H.; Hallwachs, W.; Jaffe, S.L.; Fierer, N. Caterpillars lack a resident gut microbiome. Proc. Natl. Acad. Sci. USA 2017, 114, 9641-9646. [CrossRef]

8. Ravenscraft, A.; Berry, M.; Hammer, T.; Peay, K.; Boggs, C. Structure and function of the bacterial and fungal gut microbiota of Neotropical butterflies. Ecol. Monogr. 2019, 89, e01346. [CrossRef]

9. Hammer, T.J.; Dickerson, J.C.; Fierer, N. Evidence-based recommendations on storing and handling specimens for analyses of insect microbiota. PeerJ 2015, 3, e1190. [CrossRef] 
10. Liu, Z.; DeSantis, T.Z.; Andersen, G.L.; Knight, R. Accurate taxonomy assignments from 16S rRNA sequences produced by highly parallel pyrosequencers. Nucleic Acids Res. 2008, 36, e120. [CrossRef]

11. Edgar, R.C. UPARSE: Highly accurate OTU sequences from microbial amplicon reads. Nat. Methods 2013, 10, 996-998. [CrossRef]

12. McDonald, D.; Price, M.N.; Goodrich, J.; Nawrocki, E.P.; DeSantis, T.Z.; Probst, A.; Andersen, G.L.; Knight, R.; Hugenholtz, P. An improved Greengenes taxonomy with explicit ranks for ecological and evolutionary analyses of bacteria and archaea. ISME J. 2012, 6, 610-618. [CrossRef] [PubMed]

13. Wang, Q.; Garrity, G.M.; Tiedje, J.M.; Cole, J.R. Naive Bayesian classifier for rapid assignment of rRNA sequences into the new bacterial taxonomy. Appl. Environ. Microb. 2007, 73, 5261-5267. [CrossRef] [PubMed]

14. Langille, M.G.I.; Zaneveld, J.; Caporaso, J.G.; McDonald, D.; Knights, D.; Reyes, J.A. Predictive functional profiling of microbial communities using 16S rRNA maker gene sequences. Nat. Biotechnol. 2013, 31, 814-821. [CrossRef] [PubMed]

15. Mukherjee, A.; Chettri, B.; Langpoklakpam, J.S.; Basak, P.; Prasad, A.; Mukherjee, A.K.N. Bioinformatic approaches including predictive metagenomic profiling reveal characteristics of bacterial response to petroleum hydrocarbon contamination in diverse environments. Sci. Rep. UK 2017, 7, 1108. [CrossRef]

16. Montagna, M.; Mereghetti, V.; Gargari, G.; Guglielmetti, S.; Faoro, F.; Lozzia, G.; Locatelli, D.; Limonta, L. Evidence of abacterial core in the stored products pest Plodia interpunctella: The influence of different diets. Environ. Microbiol. 2016, 18, 4961-4973. [CrossRef]

17. Ceja-Navarro, J.A.; Vega, F.E.; Karaoz, U.; Hao, Z.; Jenkins, S.; Lim, H.C.; Kosina, P.; Infante, F.; Northen, T.R.; Brodie, E.L. Gut microbiota mediate caffeine detoxification in the primary insect pest of coffee. Nat. Commun. 2015, 6, 7618. [CrossRef]

18. Padmanabha, H.; Lord, C.C.; Lounibos, L.P. Temperature induces trade-offs between development and starvation resistance in Aedes aegypti (L.) larvae. Med. Vet. Entomol. 2011, 25, 445-453. [CrossRef]

19. Cao, L.J.; Jiang, W.B.; Hoffmann, A.A. Life history effects linked to an advantage for wAu Wolbachia in Drosophila. Insects 2019, 10, 126. [CrossRef]

20. Hammer, T.J.; McMillan, W.O.; Fierer, N. Metamorphosis of a butterfly-associated bacterial community. PLoS ONE 2014, 9, e86995. [CrossRef] [PubMed]

21. Robinson, C.J.; Schloss, P.; Ramos, Y.; Raffa, K.; Handelsman, J. Robustness of the bacterial community in the cabbage white butterfly larval midgut. Microb. Ecol. 2010, 59, 199-211. [CrossRef]

22. Zaspel, J.M.; Hoy, M.A. Microbial diversity associated with the fruit-piercing and blood-feeding moth Calyptra thalictri (Lepidoptera: Noctuidae). Ann. Entomol. Soc. Am. 2008, 101, 1050-1055. [CrossRef]

23. Johnson, K.; Felton, G. Potential influence of midgut $\mathrm{pH}$ and redox potential on protein utilization in insect herbivores. Arch. Insect Biochem. Physiol. 1996, 32, 85-105. [CrossRef]

24. Jiang, H.; Vilcinskas, A.; Kanost, M.R. Immunity in Lepidopteran Insects. Invertebrate Immunity; Söderhäll, K., Ed.; Springer: New York, NY, USA, 2010; pp. 181-204.

25. Appel, H. The Chewing Herbivore Gut Lumen: Physicochemical Conditions and Their Impact on Plant Nutrients, Allelochemicals, and Insect Pathogens. Insect-Plant Interactions; Bernays, E.A., Ed.; CRC Press: Boca Raton, FL, USA, 1994; pp. 225-240.

26. Xia, X.F.; Zheng, D.D.; Zhong, H.Z.; Qin, B.C.; Gurr, G.M.; Vasseur, L.; Lin, H.L.; Bai, J.L.; He, W.Y.; You, M.S. DNA sequencing reveals the midgut microbiota of diamondback moth, Plutella xylostella (L.) and a possible relationship with insecticide resistance. PLoS ONE 2013, 8, e68852. [CrossRef] [PubMed]

27. Anand, A.A.P.; Vennison, S.J.; Sankar, S.G.; Prabhu, D.I.G.; Vasan, P.T.; Raghuraman, T.; Geoffrey, C.J.; Vendan, S.E. Isolation and characterization of bacteria from the gut of Bombyx mori that degrade cellulose, xylan, pectin and starch and their impact on digestion. J. Insect Sci. 2010, 10, 1-20. [CrossRef] [PubMed]

28. Potrikus, C.J.; Breznak, J.A. Nitrogen-fixing Entrobacter agglomerans isolated from guts of wood-eating termites. Appl. Environ. Microbiol. 1977, 33, 392-399. [CrossRef] [PubMed]

29. Zhao, B.; He, Y.L.; Hughes, J.; Zhang, X.F. Heterotrophic nitrogen removal by a newly isolated Acinetobacter calcoaceticus HNR. Bioresour. Technol. 2010, 101, 5194-5200. [CrossRef] [PubMed]

30. Zhou, S.L.; Huang, T.L.; Bai, S.Y.; He, X.X. Isolation, Identification, and nitrogen removal characteristics of oligotrophic aerobic denitrifiers. China Environ. Sci. 2016, 36, 238-348.

31. Zhou, B.; Duan, J.; Xue, L.; Zhang, J.; Yang, L. Effect of plant-based carbon source supplements on denitrification of synthetic wastewater: Focus on the microbiology. Environ. Sci. Pollut. Res. 2019, 26, 24683-24694. [CrossRef] 
32. Marmulla, R.; Harder, J. Microbial monoterpene transformations-a review. Front. Microbiol. 2014, 5, 346. [CrossRef]

33. Talia, P.; Sede, S.M.; Campos, E.; Rorig, M.; Principi, D.; Tosto, D.; Hopp, H.E.; Grasso, D.; Cataldi, A. Biodiversity characterization of cellulolytic bacteria present on native Chaco soil by comparison of ribosomal RNA genes. Res. Microbiol. 2012, 163, 221-232. [CrossRef]

34. Mereghetti, V.; Chouaia, B.; Limonta, L.; Locatelli, D.P.; Montagna, M. Evidence for a conserved microbiota across the different developmental stages of Plodia interpunctella. Insect Sci. 2019, 26, 466-478. [CrossRef] [PubMed]

35. Gandotra, S.; Kumar, A.; Naga, K.; Bhuyan, P.M.; Gogoi, D.K.; Sharma, K.; Subramanian, S. Bacterial community structure and diversity in the gut of Muga silkworm, Antheraea assamensis (Lepidoptera: Saturniidae) from India. Insect Mol. Biol. 2018, 27, 603-619. [CrossRef] [PubMed]

36. Wang, W.D.; Song, Y.B.; Wang, Y.J.; Gao, Y.M.; Jing, R.Y.; Cui, Z.J. Biodiversity of mesophilic microbial community BYND-8 capability of lignocellulose degradation and its effect on biogas production. Huan Jing Ке Хие 2011, 32, 253-258.

37. Douglas, A.E. Multiorganismal insects: Diversity and function of resident microorganisms. Annu. Rev. Entomol. 2015, 60, 17-34. [CrossRef]

38. Himler, A.G.; Adachi-Hagimori, T.; Bergen, J.E.; Kozuch, A.; Kelly, S.E.; Tabashnik, B.E.; Chiel, E.; Duckworth, V.E.; Dennehy, T.J.; Zchori-Fein, E.; et al. Rapid spread of a bacterial symbiont in an invasive whitefly is driven by fitness benefits and female bias. Science 2011, 332, 254-256. [CrossRef]

Publisher's Note: MDPI stays neutral with regard to jurisdictional claims in published maps and institutional affiliations. 